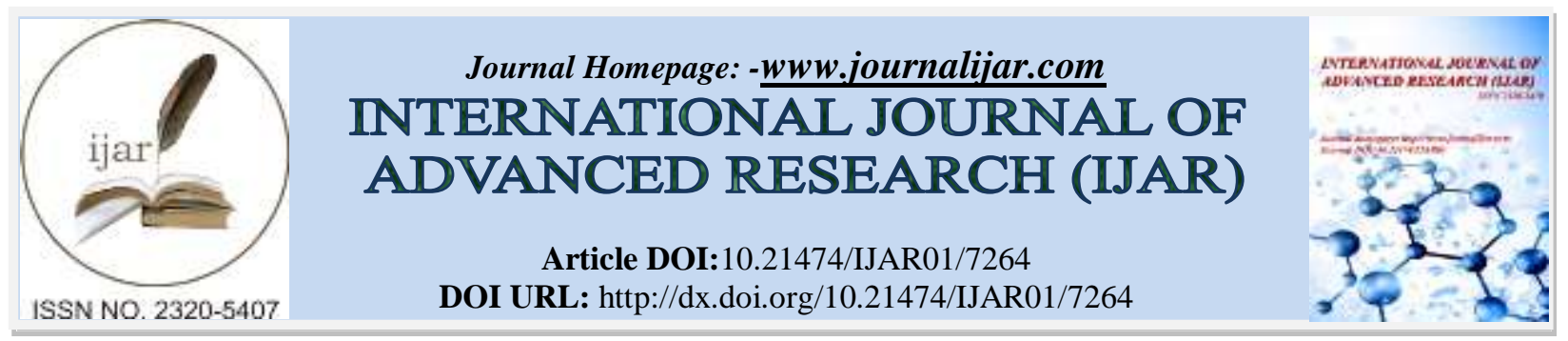

RESEARCH ARTICLE

\title{
A CASE OF LINEAR POROKERATOSIS TREATED WITH CO2 LASER.
}

Mohamed El amraoui, Naoufal Hjira and Mohammed Boui.

Department of Dermatology-Venereology, Mohammed V Military Training Hospital, Rabat, Morocco.

\section{Manuscript Info}

(..........................

Manuscript History

Received: 12 April 2018

Final Accepted: 14 May 2018

Published: June 2018

Keywords:-

Linear porokeratosis, $\mathrm{CO} 2$ laser,

keratinization disorder

\section{Abstract}

Linear porokeratosis is a rare clinical porokeratosis variant, which typically presents at birth, but can also develop in adulthood. This disorder of keratinization includes a risk of transformation into basal cell carcinoma or squamous cell carcinoma. The therapeutic arsenal is rich with variable results. We present a case of linear porokeratosis having evolved well under $\mathrm{CO} 2$ laser.

Copy Right, IJAR, 2018,. All rights reserved.

\section{Introduction:-}

Porokeratosis are rare genodermatoses characterized by a chronic disorder of keratinization responsible for variable clinical manifestations and histologically by the presence of the cornoide lamella. Among the five most common forms of porekeratosis, the linear form remains relatively rare. The diagnosis is generally easy, clinically evoked and confirmed by histology. However, the therapeutic management remains an essential step and poses some problems.

\section{Clinical case:-}

Young 30-year-old policeman, with no notable pathological antecedents. Consulted for a linear dermatitis, sitting on the lower part of the right hemiface opposite the lower mandibular area, measuring 10 centimeters in length, made of papulo-verrucous lesions hyper pigmented, not itchy and evolving for five years. The histological study of a cutaneous biopsy showed a narrow vertical column of parakeratotic corneocytes in plaice folds within a thickened and orthokeratotic horny layer, this cornoid lamella points towards the inside of the plate and rests on a depression. Of the underlying epidermis, at this level the granular layer is reduced and the underlying mucosal body contains some dyskeratotic keratinocytes. The diagnosis of a linear porokeratosis was retained. Faced with the partial improvement with topical corticosteroids and retinoids, the patient received three $\mathrm{CO} 2$ laser sessions at one month intervals with almost complete remission over 12 months of follow-up.

\section{Comments:-}

Porokeratosis is a group of infrequent, acquired or hereditary dermatosis characterized by an epidermal differentiation problem of unknown origin, probably due to the expansion of a clone of abnormal epidermal keratinocytes. Clinically characterized by atrophic patches surrounded by a hyperkeratotic ridge-like border. The histological marker is represented by the cornoid lamella. Five clinical variants are recognized: disseminated superficial actinic porokeratosis and its non actinic variant, classic porokeratosis of Mibelli, linear porokeratosis, porokeratosis palmaris and plantaris disseminata and punctate porokeratosis.

Linear porokeratosis (LP) is an infrequent variant of porokeratosis, which typically appears in childhood and which exposes the most to the risk of carcinomatous degeneration. Clinically it presents lesions of linear distribution 
following Blaschko's lines. Unilateral, bilateral and generalized forms are described. Multiple differential diagnoses can be evoked, the main ones being the epidemic nevus verrucous inflammatory linear, incontinentia pigmenti, lichen striatus and psoriasis blaschko linear. Extensive forms should seek underlying immunosuppression. In addition to the aesthetic and sometimes functional damage of porokeratoses, the risk of degeneration of porokeratosis in cutaneous carcinomas is currently accepted and estimated at 10\% [1] [2][3]. For this, multiple treatments have been tried in the treatment of porokeratosis. In the localized forms of porokeratosis the main means used are dermabrasion, cryotherapy, electrocoagulation, Imiquimod and trichloroacetic acid [1] [2]. Currently innovative techniques such as the $\mathrm{CO} 2$ laser and the dynamic phtotherapy show better results and they are in the process of detaching old therapeutics [3] [4].

\section{Conclusion:-}

Linear porokeratosis is one of the rare forms of porokeratosis which typically appears in childhood and which exposes the most to the risk of carcinomatous degeneration. In opposition to other particularly diffuse porokeratosis, the therapeutic arsenal is rich and effective. Medical lasers including the CO2 laser is very interesting alternative in the management of porokeratosis.

\section{Figure:-}

A: Linear porokeratosis of the right hemiface, after a $\mathrm{CO} 2$ laser session.

\section{Conflicts of interest:-}

The authors do not declare any conflict of interest for this work.

Authors' collaboration:-

All authors were actively involved in the development of this work.

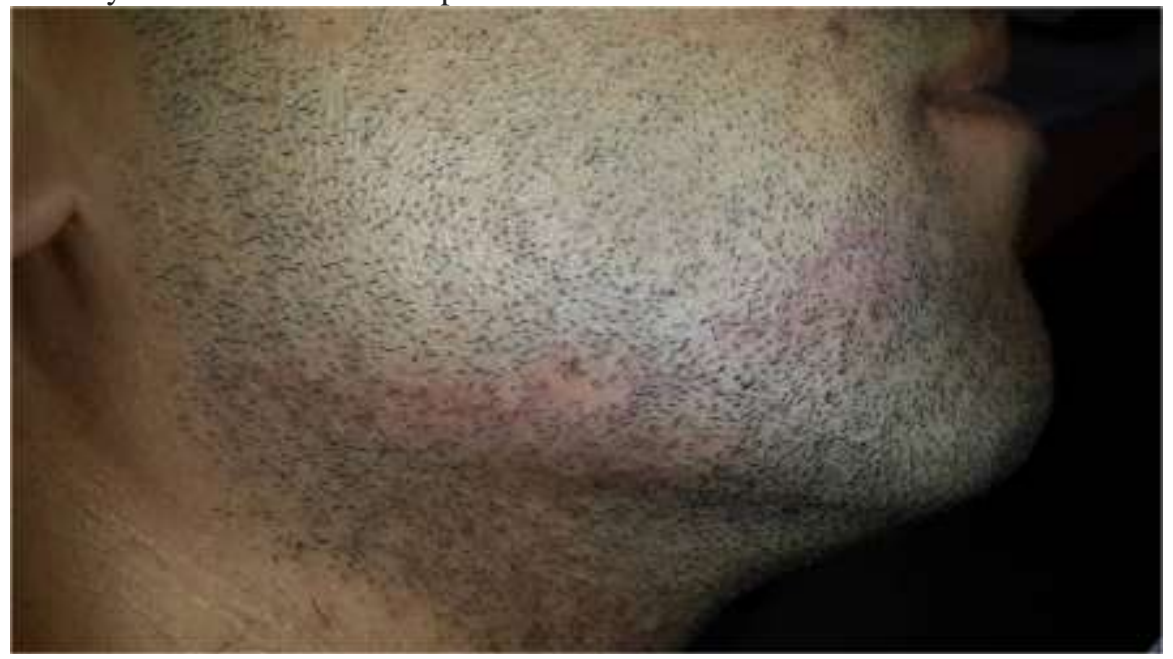

\section{References:-}

1. Slobodan Stojanovic, Marina Jovanovic, Nada Vuckovic, Milana Ivkov-Simic, Siniša Tasic. Linear porokeratosis: a case report. Serbian Journal of Dermatology and Venereology 2012; 4 (3): 105-112

2. Philip R. Cohen, Jonathan L. Held, Bruce E. Katz. Linear porokeratosis: Successful treatment with diamond fraise dermabrasion. JAAD November 1990 Volume 23, Issue 5, Part 2, Pages 975-977

3. Andrea Kovacikova Curkova, Juraj Hegyi, Peter Kozub, Zoltan Szep, Angelo Massimiliano D'Erme, Maria Simaljakova. A case of linear porokeratosis treated with photodynamic therapy with confocal microscopy $\begin{array}{llllll}\text { surveillance. } & \text { Dermatologic } & \text { therapy } & \text { Volume } & 27, & \text { Issue }\end{array}$ May/June 2014 Pages 144-147.

4. James H. Barnett. Linear porokeratosis: Treatment with the carbon dioxide laser. JAAD May 1986 Volume 14, Issue 5, Part 2, Pages 902-904. 